\title{
O MODELO SINDICAL BRASILEIRO SOB A ÓTICA SOCIOLÓGICA PÓS-MODERNA
}

\author{
Dissertação de Mestrado \\ Orientador: Prof. Dr. Paulo Eduardo Vieira De Oliveira
}

UNIVERSIDADE DE SÃO PAULO

FACULDADE DE DIREITO

São Paulo-SP

2018 


\title{
ANTERO ARANTES MARTINS FILHO
}

\section{O MODELO SINDICAL BRASILEIRO SOB A ÓTICA SOCIOLÓGICA PÓS} MODERNA

\author{
Dissertação apresentada à Banca \\ Examinadora do Programa de Pós- \\ Graduação em Direito, da Faculdade \\ de Direito da Universidade de São \\ Paulo, como exigência parcial para \\ obtenção do título de Mestre em \\ Direito na área de concentração \\ Direito do Trabalho e da Seguridade \\ Social, sob a orientação do Prof. Dr. \\ Paulo Eduardo Vieira de Oliveira
}

\section{UNIVERSIDADE DE SÃO PAULO}

FACULDADE DE DIREITO

São Paulo-SP 
Catalogação da Publicação

Serviço de Biblioteca e Documentação

Faculdade de Direito da Universidade de São Paulo

Martins Filho, Antero Arantes

O modelo sindical brasileiro sob a ótica sociológica pós-moderna / Antero Arantes Martins Filho ; orientador Paulo Eduardo Vieira de Oliveira -- São Paulo, 2018.

$89 \mathrm{p.}$

Tese (Doutorado - Programa de Pós-Graduação em Direito do Trabalho e Seguridade Social) - Faculdade de Direito, Universidade de São Paulo, 2018.

1. Direito do Trabalho. 2. Sindicatos. 3. Modernidade. 4. PósModernidade. I. Oliveira, Paulo Eduardo Vieira de, orient. II. Título. 
A Deus, pela vida, pela saúde, pelo amor, pelo propósito e por me conceder condições de realizar este trabalho.

À Regiane, minha esposa, que pelo seu amor intenso me deu o suporte emocional mesmo nos momentos mais difíceis, sem nunca deixar de ser uma excelente profissional e mãe.

À minha filha Giovana, origem de um amor imenso e dona de um amor indescritível, responsável por me conceder esperanças de que podemos tornar o mundo melhor.

Aos meus pais, Antero e Sonia, que proporcionaram todo amor e toda base e sem os quais não chegaria tão longe.

Aos meus irmãos, Pedro e Aline, que partilharam todas as minhas experiências e fizeram parte da minha caminhada. 


\section{AGRADECIMENTOS}

Agradeço à Universidade de São Paulo, por proporcionar uma estrutura excelente para o desenvolvimento dos estudos e pela qualidade de seu curso.

Aos meus professores, que pela dedicação que apresentaram, sempre me instigaram a continuar estudando.

Agradeço, especialmente, ao meu professor e orientador Paulo Eduardo Vieira de Oliveira, que acreditou no meu trabalho e, com suas lições e sua dedicação, me possibilitou chegar até aqui. 


\section{RESUMO}

Este trabalho apresenta como proposta uma análise crítica do modelo sindical brasileiro vigente sob uma ótica sociológica, a fim de melhor identificar quais são os elementos que auxiliam ou prejudicam o sindicalismo brasileiro na luta por seus direitos. Em seu primeiro capítulo, traz-se um relato histórico do modelo sindical brasileiro a partir de pesquisas bibliográficas, desde 0 surgimento dos primeiros movimentos sindicais, no final do século XIX, até os dias atuais, ressaltando as alterações na legislação vigente em cada época, passando desde a ausência de leis até o modelo mais intervencionista dos sindicatos. Em seu segundo capítulo, apresenta-se a teoria sociológica da modernidade e da pós-modernidade, baseando-se principalmente no trabalho de Zygmunt Bauman, explicando as características do Estado moderno e pósmoderno $\mathrm{e}$ as diferenças das relações trabalhistas entre empregados $\mathrm{e}$ empregadores havidas em cada época. Por fim, no terceiro capítulo, aplica-se a teoria da modernidade e da pós-modernidade no modelo sindical brasileiro, realizando-se uma análise crítica da legislação vigente e identificando-se os problemas que este modelo apresenta.

Palavras-chave: Modelo Sindical. Modernidade. Pós-modernidade. 


\begin{abstract}
This paper presents as a proposal a critical analysis of the Brazilian trade union model in force from a sociological point of view, in order to better identify the elements that help or hinder Brazilian trade unionism in the fight for their rights. In its first chapter, we present a historical account of the Brazilian union model based on bibliographical research, from the beginning of the first trade union movements in the late nineteenth century to the present day, highlighting the changes in the legislation in force at each time, from the absence of laws to the more interventionist model of the unions. In his second chapter, the sociological theory of modernity and postmodernity is presented, based mainly on the work of Zygmunt Bauman, explaining the characteristics of the modern and postmodern state and the differents labor relations between employees and employers in every season. Finally, in the third chapter, the theory of modernity and postmodernity is applied in the Brazilian union model, critically analysing the current legislation and identifing the problems that this model presents.
\end{abstract}

Keywords: Legal Union Model. Modernity. Postmodernity. 
INTRODUÇÃO

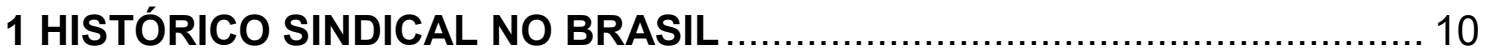

1.1 - AS PRIMEIRAS ASSOCIAÇÕES E OS PRIMEROS MOVIMENTOS ... 10

1.2 O SINDICATO NO GOVERNO DE GETÚLIO VARGAS............................. 18

1.3 O PERÍODO DEMOCRÁTICO E A CONSTITUIÇÃO DE 1946 ................. 27

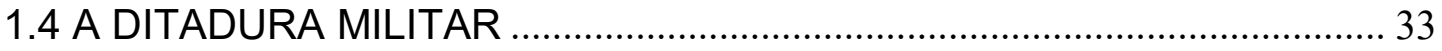

1.5 O RETORNO DA DEMOCRACIA, A CONSTITUIÇÃO DE 1988 E OS

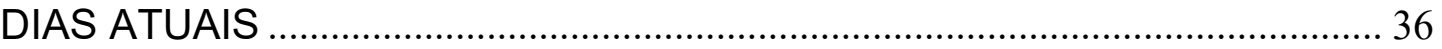

2 A MODERNIDADE E A PÓS-MODERNIDADE ........................................ 44

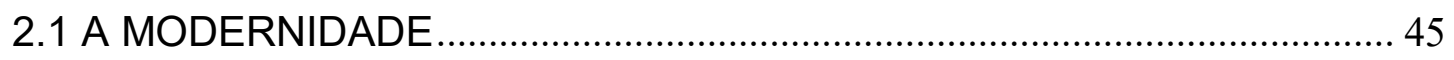

2.1.1 A modernidade e a solidez do labor do Século XIX e início do Século $\mathrm{XX}$

2.1.2 O Estado como agente da modernidade - o poder concentrado ...... 52

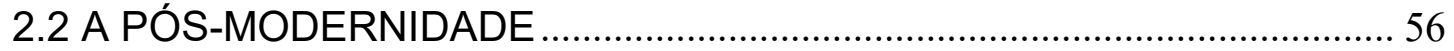

3.2.1 A pós-modernidade e a liquidez do labor do final do Século XX ....... 58

2.2.2 O divórcio entre Poder e Estado - o poder difuso do capital .............. 63

3 ANÁLISE DA TRAJETÓRIA DO MODELO SINDICAL BRASILEIRO NOS

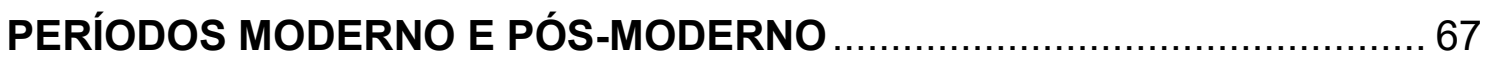

3.1 O MODELO SINDICAL BRASILEIRO NO PERÍODO MODERNO............ 67

3.2 O MODELO SINDICAL BRASILEIRO NO PERÍODO PÓS-MODERNO. 73

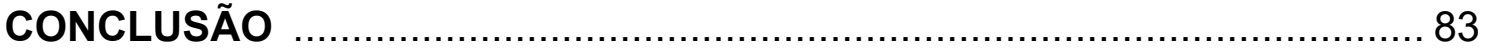

BIBLIOGRAFIA 


\section{INTRODUÇÃO}

No Brasil, atualmente, poucos são os sindicatos combativos que se impõem na luta pelos direitos daqueles que representam. Muitos deles exercem função basicamente assistencialista, enquanto que a legislação se constitui na principal fonte de direitos dos trabalhadores.

A representatividade destes sindicatos, por sua vez, também é baixa, considerando que se constata que a taxa de sindicalização encontra níveis insatisfatórios.

Há, portanto, uma evidente crise do sindicalismo autônomo, na união espontânea de trabalhadores que possuem objetivos em comum.

Diversos doutrinadores consideram o modelo sindical brasileiro a principal causa desta inércia sindical atual, criticando-o por diversos motivos diferentes, havendo aqueles que indiquem como ideal a pluralidade sindical, enquanto outros entendem pela unicidade. Há ainda os que defendam a extinção do financiamento compulsório dos sindicatos e outros que a entendem pela sua permanência, entre outros aspectos.

Assim, é preciso se debruçar sobre o modelo sindical brasileiro, a fim de melhor compreendê-lo e identificar os aspectos positivos e negativos que esse possui.

Desde o início dos movimentos sociais no país até os dias de hoje, o modelo sindical brasileiro sofreu diversas modificações, assumindo diferentes características, ora sem regulamentação, ora tratando-se de um modelo mais restrito, as intervenções estatais.

Para melhor compreender o modelo sindical atual, necessário se faz entender o contexto histórico em que os sindicatos surgiram e em quais 
condições o modelo sindical brasileiro foi concebido e por quais alterações passou ao longo da história.

Contudo, uma análise puramente histórica e jurídica do modelo sindical não se mostra suficiente para identificar os problemas existentes, sendo necessário compreender as características da sociedade atual e como ela reage ao modelo sindical vigente.

Esta sociedade atual igualmente passou por profundas transformações, notadamente nas relações trabalhistas.

Portanto, para se compreender o modelo sindical brasileiro, bem como para conseguir identificar quais de suas características são responsáveis por auxiliar a união de trabalhadores em sindicatos e quais são responsáveis por prejudicá-la, é necessário entender as características da sociedade em que esse modelo sindical está inserido.

A fim de realizar uma leitura destas alterações da sociedade, focada nas relações de trabalho, mister se faz um estudo da sociologia contemporânea, examinando as características dos períodos da modernidade e da pósmodernidade.

Para este fim, escolheu-se pautar o presente trabalho na teoria de Zygmunt Bauman, sociólogo polonês, o qual apresenta um pensamento crítico do período moderno e pós-moderno, sem descartar as contribuições feitas por outros autores que também abordam o assunto.

Verifica-se a importância do tema nos tempos atuais, uma vez que o Estado brasileiro recentemente promulga leis que fortalecem as negociações coletivas em detrimento das proteções legais, retirando-se da condição de principal fonte dos direitos trabalhistas. 
Neste contexto, é de suma importância que os sindicatos tenham força para reivindicar direitos e defender os interesses de seus trabalhadores, sob pena de se aprofundar uma desigualdade existente nas relações de trabalho em virtude da alteração da fonte primária dos direitos trabalhistas.

Contudo, questiona-se se o modelo sindical brasileiro atual cria condições para que os sindicatos possam cumprir de maneira satisfatória este papel que lhes é atribuído.

Em virtude disso, este trabalho se propõe a estudar o modelo sindical brasileiro e a sociedade atual, a fim de descobrir se este propicia condições para um sindicalismo forte e capaz de lutar pelos direitos dos trabalhadores. 


\section{CONCLUSÃO}

No contexto histórico atual pós-moderno, frente à independência alcançada pelos representantes do capital em relação aos trabalhadores em virtude da tecnologia, a desigualdade havida entre as partes é naturalmente acentuada.

Sempre houve a necessidade de um poder que equilibrasse as relações entre o capital e o trabalho. Porém, com um capital mais forte, nunca este poder foi tão necessário.

Tal poder foi historicamente exercido pelo Estado, que foi a fonte primária dos direitos trabalhistas, agindo sempre no sentido criar condições mínimas aos trabalhadores

Contudo, o período pós-moderno é caracterizado pela economia globalizada, em que o capital não se prende mais a um Estado-nação, podendo locomover-se, em questão de pouco tempo, de um local para outro, tornando seus movimentos imprevisíveis.

Somando-se à perda de objetivo dos Estados do período moderno e a decadência dos metarrelatos, observa-se haver um deslocamento de poder, que antes era concentrado no Estado e passa a ser difundido pelos detentores do capital.

Sem o poder que antes possuía, o Estado se vê incapaz de fixar o capital, perdendo o poder notadamente na intervenção nas relações de trabalho. Em decorrência desta gradativa perda do poder, o Estado perde ainda o interesse em servir como agente de equilíbrio das relações trabalhistas.

Tais constatações claramente se aplicam ao caso do Estado brasileiro, que como consequência, passa a atuar no sentido de deixar de regular as 
relações de trabalho. Estas, cada vez mais desiguais no período pós-moderno, carecem mais daquele poder que equilibre a força entre as partes.

O Estado deixa de exercer este poder concentrado que antes the era incumbido, deixando um vácuo que deverá ser preenchido pelos atores sociais das relações trabalhistas.

Nesse contexto, os sindicatos adquirem ainda mais importância, uma vez que os representantes do capital se encontram mais fortes do que jamais foram no período moderno.

Os sindicatos devem assumir o papel de fonte primária dos direitos trabalhistas, não somente para conquistar novos direitos, mas também para impedir o perecimento dos que foram conquistados.

É em virtude desta importância que o modelo sindical brasileiro se destaca, pois deveria criar condições para que os sindicatos possam exercer o seu papel de equilíbrio das relações trabalhistas.

Contudo, o que se demonstra é que o modelo sindical brasileiro, atualmente, não reúne condições necessárias para cumprir com este objetivo, por diversos motivos.

Manteve-se a limitação ao exercício da liberdade sindical, através da unicidade sindical, bem como da divisão por categorias/território.

Ainda, torna-se desnecessária a participação do sindicato em questões importantes como as demissões coletivas, as homologações de rescisões e a possibilidade de realização de acordos individuais.

Ademais, extinguiu-se o financiamento compulsório, sem a criação de políticas para estímulo de sindicalização, criando condições para que os sindicatos fracos se tornem corruptíveis. 
Assim, o modelo sindical brasileiro, apesar de apresentar pontos importantes em virtude da autonomia sindical, como a inexistência de a intervenção Estatal do poder executivo e relativização do poder normativo, bem como a proteção ao empregado ocupante de cargo de direção de sindicato, não apresenta ainda a liberdade sindical plena, necessária para o surgimento e manutenção de sindicatos representativos, em virtude das características acima nomeadas.

Nota-se que o modelo sindical, além de restringir a atuação dos sindicatos, desestimula a sua participação e a sua filiação, agravando ainda mais uma situação já fragilizada pelas condições naturais das relações trabalhistas.

Os sindicatos, atualmente, não possuem poder para fazer frente aos interesses das empresas, de modo que são incapazes de substituir o Estado na função de poder de equilíbrio das partes.

Se este quadro não se reverter, haverá um crescimento na desigualdade entre as partes nas relações trabalhistas, levando-se ao esgotamento e podendo causar consequências sociais gravíssimas, uma vez que a tendência é que os avanços tecnológicos aumentem ainda mais a independências dos representantes do capital em relação aos trabalhadores.

É necessário que atitudes sejam tomadas para que sejam criadas condições que estimulem a filiação dos trabalhadores a sindicatos, reagindo à tendência pós-moderna de atomização das relações. 


\section{BIBLIOGRAFIA}

ALVES, Paulo. O anarquismo e o Estado no Brasil no início do século $X X$. Projeto História (PUCSP), São Paulo, v. 6, p. 41-54, 1986.

AROUCA, José Carlos. Organização Sindical no Brasil/passado, presente e futuro (?). São Paulo: LTr, 2013.

Curso básico de direito sindical. 2. ed. São Paulo:

Ltr, 2009.

BALTHAZAR, Ricardo. Três ações de inconstitucionalidade questionam artigos da nova lei no STF. Jornal Folha de São Paulo, 12 nov. 2017. Caderno Mercado.

Disponível

em:

http://www1.folha.uol.com.br/mercado/2017/11/1934722-tres-acoes-de-

inconstitucionalidade-questionam-artigos-da-nova-lei-no-stf.shtml. Acesso em: 11 dez. 2017.

BAUMAN, Zygmunt. Modernidade Líquida. Rio de Janeiro: Jorge Zahar Editor, 2001.

. O Mal-Estar da Pós Modernidade. Rio de Janeiro:

Zahar,1998.

A Sociedade Individualizada: vidas contadas e histórias vividas. Tradução de José Gradel. Rio de Janeiro: Zahar. Ed, 2008.

Capitalismo parasitário: e outros temas contemporâneos. Tradução de Eliana Aguiar. Rio de Janeiro: Zahar Ed, 2010.

Comunidade: a busca por segurança no mundo atual. Tradução de Plínio Dentzien. Rio de Janeiro: Jorge Zahar Ed., 2003. 
. Globalização: as conseqüências humanas. Tradução de Marcus Penchel. Rio de Janeiro: Jorge Zahar Ed., 1999

. Modernidade e Ambivalência. Tradução de Marcus Penchel. Rio de Janeiro: Jorge Zahar Ed., 1999

BITTAR, Eduardo Carlos Bianca. O Direito na Pós-modernidade. Revista Seqüência, n. 57, p. 131-152, dez. 2008

DELGADO, Maurício Godinho. Curso de Direito do Trabalho. 13. ed. São Paulo LTr. 2014.

FAUSTO, Boris. História do Brasil 2. ed. São Paulo: Editora da Universidade de São Paulo: Fundação e Desenvolvimento da Educação, 1995.

GOMES, Orlando; GOTTSCHALK, Elson. Curso de Direito do Trabalho. 17. ed. Rio de Janeiro: Forense, 2006.

HABERMAS, Jüegen. 0 discurso filosófico da modernidade: doze lições. Tradução de Luiz Sérgio Repa e Rodnei nascimento. São Paulo: Martins Fontes, 2000.

HORN, Carlos Henrique; SILVA, Sayonara Grillo Coutinho Leonardo da. (orgs.) Ensaios Sobre Sindicatos E Reforma Sindical No Brasil. São Paulo: Ltr, 2009.

JORGE NETO, Francisco Ferreira; CAVALCANTE, Jouberto de Quadros Pessoa. Direito do Trabalho. 6. ed. São Paulo: Atlas, 2012.

LIPOVETSKY, Gilles. Os tempos hipermodernos. Tradução de Mário Vilela. São Paulo: Editora Barcarolla, 2004. 
LYOTARD, Jean-François. A condição pós-moderna. Tradução de Ricardo Corrêa Barbosa. 12. ed. Rio de Janeiro: José Olympio, 2009.

MAGANO, Octavio Bueno. Fundamentos do Direito Coletivo do Trabalho. Revista da Faculdade de Direito da Universidade de São Paulo, São Paulo, v. 73 p. $115-125,1978$

MALISKA, Marcos Augusto. Marx Weber e o Estado Racional Moderno. Revista Eletrônica do CEJUR, v. 1, n. 1, p. 15-28, ago/dez. 2006. Disponível em: http://revistas.ufpr.br/cejur/article/view/14830/9954. Acesso em: 24 out. 2017.

MORAES FILHO, Evaristo de. O problema do sindicato único no Brasil (seus fundamentos sociológicos. Rio de Janeiro: A Noite, 1952.

O problema de uma sociologia do Direito.

Rio De Janeiro: Freitas Bastos, 1950.

NAKAGAWA, Fernando. MP da Reforma trabalhista já recebeu recorde histórico de emendas. Jornal Folha de São Paulo, São Paulo, 21 nov. 2017. Caderno Economia e Negócios. Disponível em: http://economia.estadao.com.br/noticias/geral,mp-que-ajusta-reformatrabalhista-ja-recebeu-mais-de-300-emendas-no-congresso,70002092184. Acesso em: 11 dez. 2017

NASCIMENTO, Amauri Mascaro. Curso de Direito do Trabalho: história e teoria geral do direito do trabalho: relações individuais e coletivas do trabalho. 27. ed. São Paulo: Saraiva, 2012.

PRIORI, A., et al. A Ditadura Militar e a violência contra os movimentos sociais, políticos e culturais. A História do Paraná: séculos XIX e XX [online]. Maringá: Eduem, 2012.. pp. 199-213. 
ROMITA, Arion Sayão. Sindicalismo, economia, estado democrático: estudos. São Paulo: LTr, 1993.

SANTOS, Boaventura de Sousa. Para um novo senso comum: a ciência, o direito e a política na transição paradigmática. 4. ed. São Paulo: Cortez, 2002.

SANTOS, Ronaldo Lima dos. Sindicatos e ações coletivas: acesso à justiça coletiva e tutela dos interesses difusos, coletivos e individuais homogêneos. 4. ed. São Paulo: LTr, 2014.

- Sindicalismo no Brasil: do Corporativismo ao neocorporativismo - a questão das centrais sindicais. Revista LTR: Legislação do Trabalho, São Paulo, v. 77p. 1336 - 1347 nov.2013.

SEVERO, Valdete Souto; MAIOR, Jorge Luiz Souto. Manual da Reforma Trabalhista: pontos e contrapontos. São Paulo: Sensus, 2017.

STEINMETZ, Wilson. A Era Vargas: uma avaliação a partir da estrutura sindical dos direitos Trabalhistas - Suplemento Trabalhista n¹09/08 São Paulo LTR: 2008.

SÜSSEKIND, Arnaldo Lopes. et al. Instituições de Direito do Trabalho. 21. ed. São Paulo: Editora LTR, 2003. v. 2.

VIANA, José de Segadas. Direito Coletivo de Trabalho. São Paulo: LTr., 1972

VIDIGAL, Iracema Linek. A questão da unicidade sindical no Brasil. 2005. 64 f. Tese (Mestrado da Faculdade de Direito da USP) - USP, São Paulo, 2005 